LJUPKO ŠIMUNOVIĆ, Ph.D.

E-mail: ljupko.simunovic@fpz.hr IVAN BOŠNJAK, Ph.D.

E-mail: ivan.bosnjak@fpz.hr

SADKO MANDŽUKA, Ph.D.

E-mail: sadko.mandzuka@fpz.hr

University of Zagreb,

Faculty of Transport and Traffic Sciences

Vukelićeva 4, HR-10000 Zagreb, Republic of Croatia
Intelligent Transport Systems (ITS)

Review

Accepted: May 16, 2008

Approved: Mar. 11, 2009

\title{
INTELLIGENT TRANSPORT SYSTEMS AND PEDESTRIAN TRAFFIC
}

\begin{abstract}
The paper gives an overview of the past development and implementation of Intelligent Transport Systems in pedestrian traffic. Starting from recent development projects and methodological approaches to the development of ITS, an overview of the existing technologies of implementing ITS in pedestrian traffic is given, and some solutions are proposed that would be feasible in the Republic of Croatia, as well as in other transition countries. As the most significant functions of integrated systems within ITS, the possibilities are presented of locating pedestrians in the network, pedestrian guidance (especially the blind and low-vision persons as well as persons in wheelchairs), provision of on-trip information, etc. Special focus is on the area of pedestrian protection in traffic (avoidance of accidents) using devices fitted onboard vehicles and embedded in road infrastructure. The significance of timely integration of the pedestrian traffic in designing the future ITS architecture has been indicated.
\end{abstract}

\section{KEY WORDS}

intelligent transport systems (ITS), pedestrian traffic, pedestrian guidance, real-time information, traffic safety

\section{INTRODUCTION}

Walking is the foundation of every movement, either as the main mode or as addition in the chain of complex multi-modal movement. Any movement of people starts and ends by walking which means that it is included in every traffic mode.

While performing movement the pedestrians and the vehicles often share common surfaces, which causes numerous problems to both. By moving along the same surfaces the pedestrians are exposed to traffic incidents, noise, exhaust gases and substantial time losses. In order to ensure equality of conditions all the traffic participants should be treated in the same way. Favouring of any traffic mode at the expense of an- other, results eventually in non-functional and non-efficient solutions of general mobility. The existing solutions of intelligent transport systems in the world include equally the user services for the pedestrians as well. In this sense, the greatest improvement was made in Japan, where ITS support for pedestrians has been isolated as a separate development area.

The improvements obtained by the application of ITS approach can be quantitatively expressed through the indicators of improving the quality of services, increase in the efficiency and general improvement of pedestrian traffic safety. Here, special importance is on the possibilities of ITS in pedestrian guidance and avoidance of pedestrian-vehicle accidents. As the most important functions of integrated sub-systems within ITS, the focus is on the possibilities of locating pedestrians in the network, provision of on-trip information especially to blind persons in order to make them avoid dangerous spots, guidance of persons in wheelchairs as well as protection of pedestrians using the devices fitted onboard vehicles and embedded in the road. The paper shows the basic principles and technologies of this relatively new approach to raising the quality of people mobility.

\section{BASIC CHARACTERISTICS AND DEVELOPMENT OF INTELLIGENT TRANSPORT SYSTEMS}

Frequently, the misconception in the wider professional community is the opinion that the existing partially applied road telematic solutions represent ITS. This is far from true, since it is the integration of individual telematic systems with the support of advanced algorithms of information processing, that one may speak about the ITS paradigm [1]. Transportation systems upgraded by the information and telecommunication equipment have received the attribute "intelli- 
gent" since in the future solutions they are expected to feature the capabilities of learning, reasoning and adapting to traffic environment.

The initial step in ITS development is the building of the respective architecture. The contribution of architecture is crucial in the initial phase of system design when the users requirements and possible solutions have to be defined and harmonized, the standards and recommendations from the respective industries, construction, telecommunication, electronics, etc. defined. [2]. Since ITS architecture represents the structural hierarchy of the future system, it has to anticipate the future development of diverse equipment that is going to be used. The creation of national architecture is estimated to require 1-2 years, and regional ones 6-12 months [3]. The creation of national ITS architecture requires participation of all the stakeholders such as government administrations, scientific institutions, tourist agencies, local and financial communities, network operators, providers (owners) of transportation services and other interested users. The participants in the developing of the frames of the future ITS architecture are expected to be highly professional, creative and have vision regarding ITS development.

Due to the size and complexity of intervention in the development and implementation, the introduction of ITS has to be methodically prepared and well managed. The usual practice in transition countries when introducing ITS is the work in phases, using the step-by-step principle. The existing telematic equipment, which fits into the future required standards, is kept and if necessary upgraded. The problems that may occur are the incompatibility of the installed equipment and impossibility of its upgrade. The special actual problem in these upgrades is the resistance of the investors who are reluctant to change it before the return of the previous investments is completed.

The majority of the developed countries in the world today have a built national architecture such as America, Japan, Australia, etc. In the European Union there are significant problems in defining a unique ITS architecture. Here, a special problem is that some member countries have started their own developments. The following separate projects are known: France - ACTIF (Architecture Cadre pour le Transport Intelligent en France), Norway - ARKTRANS, Italy - ARTIS (Architettura Telematica Italiana per il Sistema dei Trasporti), Finland - TelemArk, the Czech Republic - TEAM PROJECT, Austria - TTS-A (Transport Telematics System - Austria) and the Netherlands - AVB/STIS/Koepel. In Sweden, Spain, Switzerland, Slovenia, Slovakia, Poland, Hungary, etc. ITS architecture is in the phase of development and studying. Great Britain has not yet defined a unique national architecture, but there are initiatives to unify its regional architectures [4,5,6,7].
The European Commission has brought a number of measures and recommendations for the building of a unique European ITS architecture. Thus, in 1994 it brought an ITS architecture programme entitled SATIN (System Architecture and Traffic Control Integration) $[8,9]$ suggesting a large number of measures to improve the road infrastructure in order to increase safety and transport efficiency. A new project entitled CONVERGE $[8,10]$ in 1996 has revised the program SATIN and is upgraded by the system architecture for rail, water, and air traffic. The European Commission has continued its research and in 1998 produced a draft of the Pan-European system architecture KAREN (Keystone Architecture Required for European Networks) [8.11] based on the methods developed in SATIN and CONVERGE. During 2000/01 the KAREN project was updated several times, expanded and improved and it is considered the predecessor of the new project of the European ITS architecture "European ITS Framework Architecture". Today, two projects of the European ITS architecture are active, known under the title FRAME-NET and FRAME-S [11,12]. A series of proposals are yet to be expected from the European Commission regarding the harmonization of the differences and incompatibilities of national architectures across Europe and the world. Figure 1, in compliance with literature [4], presents the basic components of ITS architecture.

The focus on technical issues i. e. on the telematics equipment without considering the functional connection can lead in the wrong direction. It may happen that the installed equipment does not provide the expected services or the information is not given to those

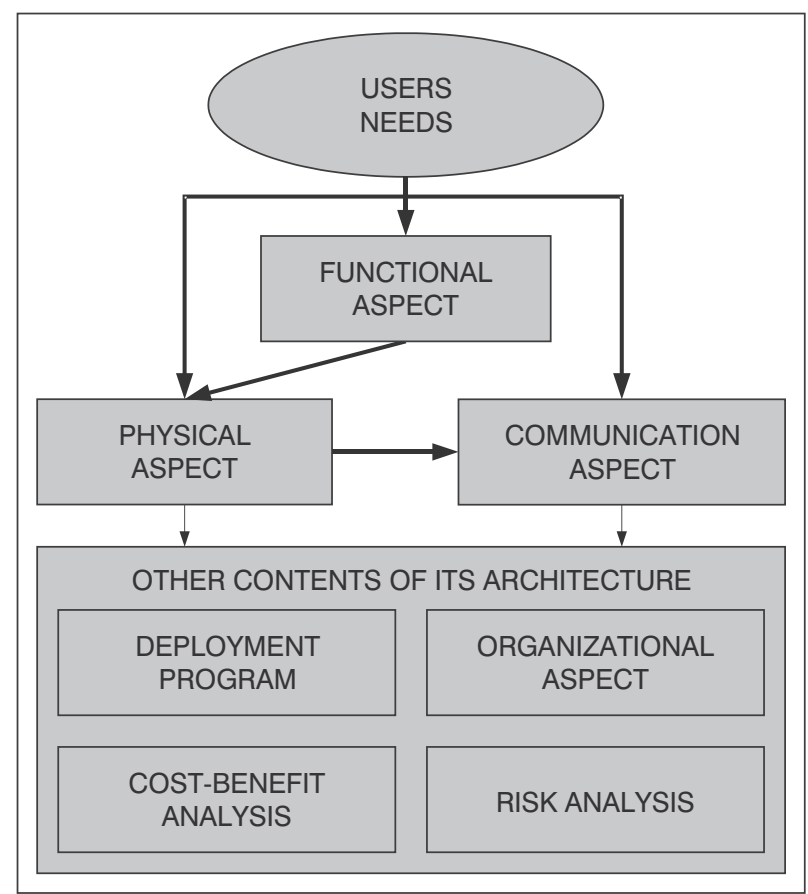

Figure 1 - Basic components of ITS architecture 
who need them. Such technologies become then islands with no communication between them, and this may multiply increase the costs and restrict their use. In order to minimize the risks of bad solutions attention should be paid to the following requirements.

- Compatibility, which means that software support, or the devices in the system can be modified or upgraded, with the system continuing to function and not losing on the quality of service;

- Expansibility, which is very similar to compatibility, and means that the system, in case more work and new tasks are needed, can be successfully expanded (upgraded by new equipment, software support);

- Interoperability is the capability of two or several systems to exchange and use the exchanged information (IEEE definition). The issue of interoperability is especially studied when it is necessary to connect different operators or systems from different regions or countries. Such examples are the charging of toll, fares or parking in different countries, by using smart cards. In such cases it is necessary to adopt and harmonize the standard for technological, administrative and financial processes. This may also mean the development of a common architecture or their parts;

- Integrability is the possibility of connecting and harmonizing the work of several systems into one. A unique integrated system that is multiply feasible is more cost-efficient than the building of individual subsystems. The integration of the existing applications is much more difficult and complex than the building of a completely new integrated system;

- Standardization is the necessary precondition to achieve successful realization of ITS in the total lifecycle of these systems [13,14,15].

Apart from the mentioned requirements, successful ITS should be purposeful, feasible, reliable, precise, safe and socially acceptable.

\section{IMPLEMENTATION OF ITS IN PEDESTRIAN TRAFFIC}

By using of the advanced ITS technologies that represent the upgrade of the classical traffic engineering, new values for all the pedestrians are created, and especially for those with special needs who have to be provided smooth movement free of barriers. The legislation of the European Union member countries $[16,17]$ defines a person as the person with special needs, if there is certain threat to the body functions, or mental capabilities over a period longer than 6 months from the state normal for the respective age, assuming that this has created a real barrier for nor- mal participation of that person in everyday social life. The improvements related to the usage of ITS are usually expressed through the following indicators [18]:

- shortening of the travel time,

- reduction of the travel costs,

- reduction in the number of incidents,

- reduction of negative impact on the environment,

- increase in the comfort and satisfaction of pedestrians,

- increase of capacity,

- development of industry.

Some of the mentioned indicators can be easily quantified, whereas for the more complex ones various estimation methods are used, based on the fuzzy approach and artificial neuron networks.

\subsection{Behaviour and requirements of pedestrians}

For better understanding of the users requests, it is necessary to collect data on the behaviour of pedestrians in traffic regarding their age, gender, size, purpose of movement, medical condition, etc. In order to analyze these data various methods of statistical studies, intelligent algorithms of prediction (analysis trend) and various methods of identifying typical samples (method of support vectors, artificial neuron networks, etc.) are used. Since pedestrian flows include also the persons with special needs, their requirements have to be considered as well. Based on the clearly defined requirements it is possible to define the functional flows of data and to make a decision on the correct selection of the telematics equipment to solve the users requests.

The pedestrians who have certain difficulties in traffic can be divided into two groups:

- Pedestrians with difficulties in a wider sense (children, seniors, pregnant women, pedestrians with luggage and baby carriages);

- Pedestrians with difficulties in a narrower sense (physically disabled, persons with low vision, impaired hearing and mental disorders).

Each of the mentioned groups has a specific behaviour. Children have sudden and irregular reactions so that, apart from the solutions offered by ITS, they need an adult supervisor. Senior persons, however, have reduced mobility and strength and they need more time to cross the street, they have weaker reflexes, reduced eyesight and hearing, limited attention and memory. The blind use a stick and guide dogs. They orient themselves by touch or contact and sense of hearing. They need more time to cross the street. They also have difficulties in maintaining the direction of path at the intersection. The loss of hearing is not a significant barrier in traffic like the loss of sight. These 
users rely mainly on visual indicators and they need large visibility field and an environment free of visual obstructions. The persons with mental difficulties have limited possibilities of observation, identification, understanding, interpretation and reaction to information. Most often they cannot read and therefore it is recommendable to use pictures, symbols and colours as signs in traffic. For instance, it is better to use a pedestrian animation on the signal indicator (signal controlled intersection) than to write out the message "GO".

Based on a detailed analysis of the behaviour of pedestrians in traffic and their requirements, it is possible to find suitable solution within ITS and thus to satisfy the users. Efficient linking of the users requirements on the one hand and the offered solutions on the other, depends to a large extent on the quality of the available information.

\subsection{Locating pedestrians}

For a more efficient functioning of the pedestrian traffic, continuous collecting and processing of real-time data on traffic are necessary. Therefore, special importance lies on the comprehensive connection of pedestrians, vehicles and road into a single information and telecommunication network. Based on the current location of pedestrians and vehicles on the road it is possible to improve the guidance and safety of pedestrian traffic flows.

Three important possibilities provided by ITS include locating, mapping (assigning position to the map), and communication between the components of the system and environment not belonging to the system itself. For locating i. e. precise determination of the position of any object on Earth (land, sea, and air - space close to the Earth) at any moment, as well as for determination of the current position and speed of a moving object the satellite navigation systems are used, mostly GPS (Global Positioning System). Today, apart from military purposes, which was the original incentive for developing the system, GPS receivers are also used in everyday civil life, including traffic for the positioning and controlling of traffic and transport means, reloading mechanisation and logistics units (pallets, containers), for planning of travelling routes, reporting and analysis of traffic accidents, etc. Successful application of GPS technologies for the positioning and monitoring pedestrian movement on certain network or area is much improved by using GIS technology (Geographic Information System). Combining GPS and GIS technology into a unique system ensures monitoring of mobile objects / subjects in real time and displaying of the accurate position of objects / subjects on an adequate geographic map with the addition to many geo-referenced data.
The information on the position of pedestrians or vehicles can be obtained also by collecting data by means of sensors fitted onboard vehicles, in the roads and on the pedestrian equipment (there is an initiative in Japan to fit the school bags with "tracking tags" so that the parents would know where their children are; women in England who move through dangerous city districts install locating sensors in their rings for security reasons). The sensor data are transferred to the control centre where these are processed and returned back to the driver or the pedestrian.

Determining of the current location of the pedestrian is especially important in emergency cases when the pedestrian needs urgent assistance (heart attack, pedestrian mugging), but also in cases of navigation in order to determine the point of origin of walking, etc. The service request is made by simple push on the mobile device button which determines the current location, and forwards the call for help towards the police, emergency services, etc.

\subsection{Intelligent information systems for pedestrians}

Traffic is a dynamic process which continuously changes in space and time. The role of real-time information in this process is inevitable. The real-time information inform the users about the arrival and departure of vehicles, possibilities of changing, location of vehicles, congestion and delays of vehicles, schedules, fares, routes, as well as other information such as time, date, weather forecast, etc. Based on timely and accurate information the users make decisions on optimal time of departure, travel method, selection of the travel route, change of destination or cancel the trip, presented in Figure 2.

Figure 3 shows an example of research and the related results of the impact of real-time information on the users, obtained by research in Seattle [19].

According to these studies the users think that the biggest advantages include the possibility of shortening the trip time (43\%), better planning of departure $(13 \%)$, reduction of stress $(12 \%)$, increase in travelling safety (6\%), avoidance of congestion, etc. (8\%) (Figure 4).

The key factor of success of real-time information is the system of Automatic Vehicle Location - AVL, i. e. location of pedestrians presented in Figure 5.

Using the satellite-provided data the GPS receiver calculates the location of the vehicle or pedestrian within $3 \mathrm{~m}$ to $6 \mathrm{~m}(10 \mathrm{ft}-20 \mathrm{ft})$ [21]. The precision of locating the vehicle or pedestrian can be improved by using differential GPS - DGPS (Differential Global Positioning System). The read data are sent to the centre via the Internet or by using the mobile telephony network - GPRS (General Packet Radio Ser- 


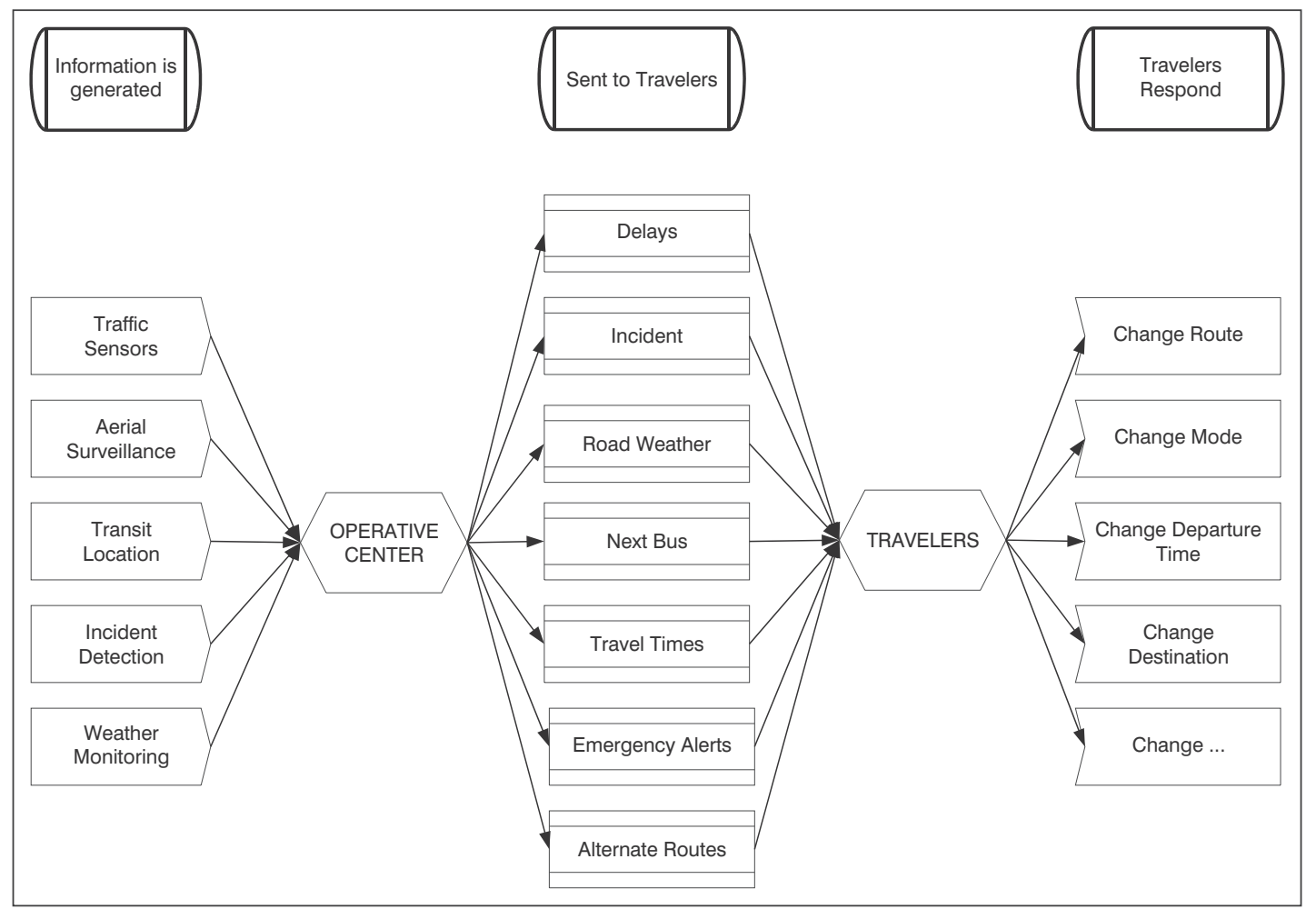

Figure 2 - Influence of timely information on decision making

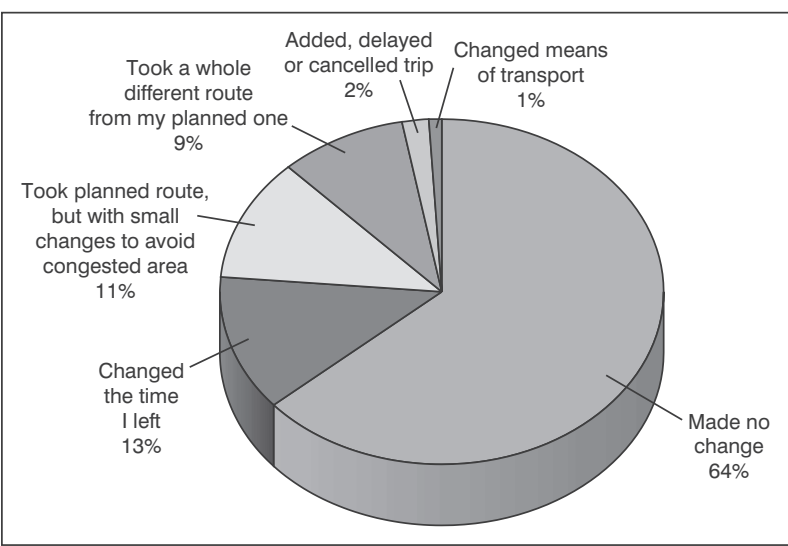

Figure 3 - Impact of travel information on the users [19]

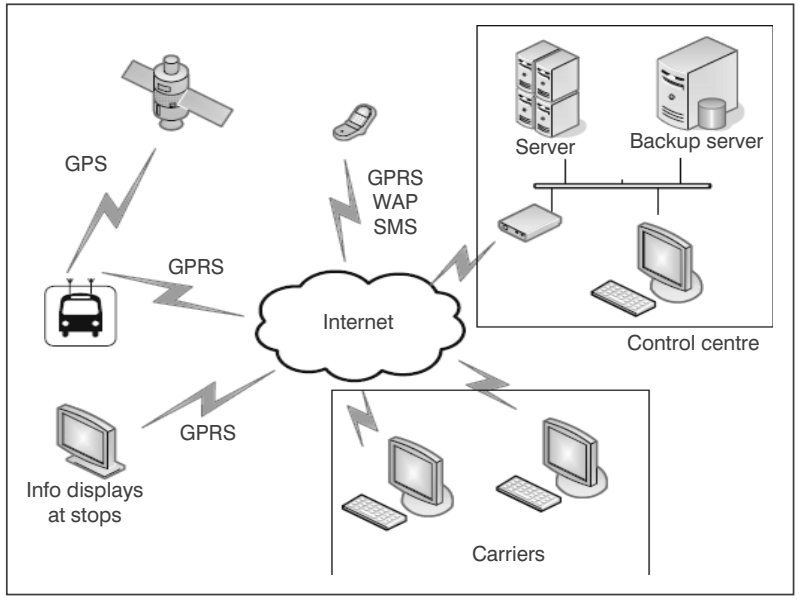

Figure 5 - Components of pedestrian tracking system [20]

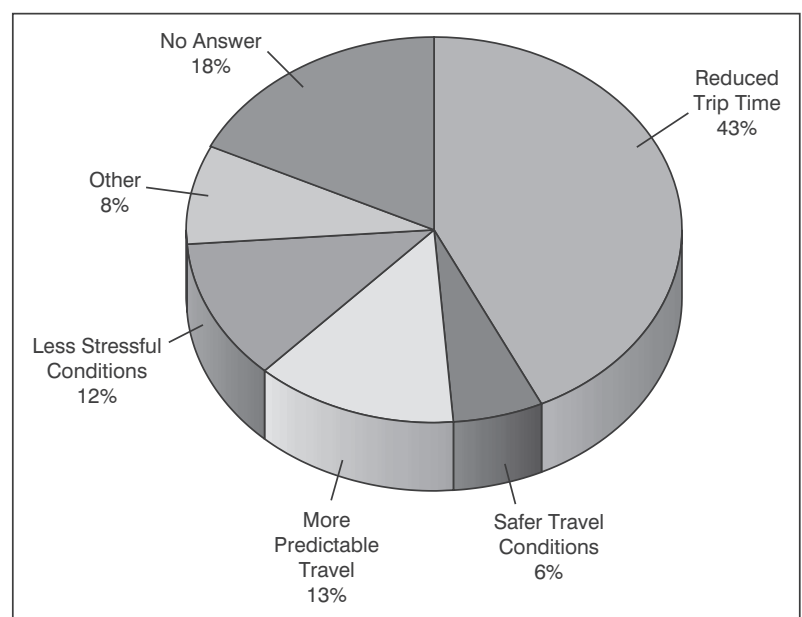

Figure 4 - Benefits of travel information [19]

vice). The processed information is distributed to the users by means of interactive and non-interactive media.

The user may obtain information prior to the trip (pre-trip information), during the trip (on-trip information) and at the end of the trip (end-trip information). The pre-trip information received before the departure of the train or bus, at the office or at home may be used by the traveller for good preparation of the trip or for other activities. Figure 6 shows the pre-trip informing via WEB (Internet) or WAP (Wireless Application Protocol).

For the pedestrian at a stop the most important information is the prediction of the vehicle movement, 


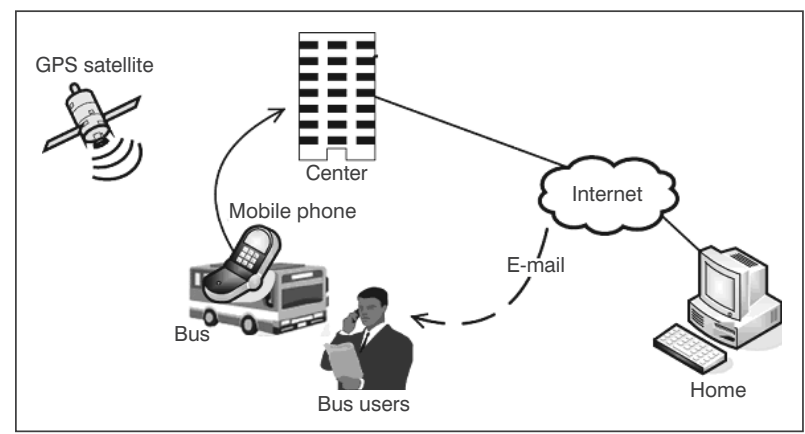

Figure 6 - Pre-trip information [22]

i.e. estimate of public transit vehicle time of arrival to the stop. Such information is obtained by means of various information displays or video monitors (VMS - Variable Message Signs / DMS - Dynamic Message Signs), cable television, internet, telephone, PDA (Personal Digital Assistants), terminals, etc. Recent research carried out in London as part of the "LLAMD" project [23] shows the following:

- $90 \%$ of respondents think that the travellers need the information about the vehicle arrival,

- $65 \%$ of travellers have the feeling that the waiting time is shorter when they are informed about the vehicle arrival,

- $85 \%$ consider the waiting time acceptable when they have the information,

- $64 \%$ believe in the public transit improvement from the moment of introducing the information system.

Figure 7 shows the announcement of the arrival of the public transit vehicle by means of information display. The announcement can also be made by voice which is very important for the blind persons

For the riders in a vehicle the obtained information significantly raise the quality of the public transit service. A research carried out in Montreal after the implementation of the information provision service onboard public transit vehicles showed that $88 \%$ of

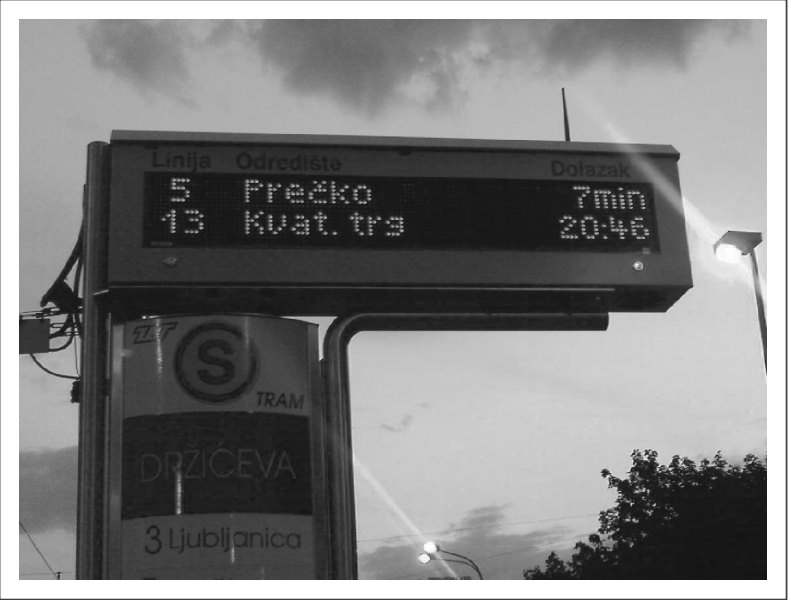

Figure 7 - Information panel at the Zagreb public transit stop travellers considered the trip more comfortable, and $72 \%$ as good or excellent [23]. During the ride, the messages can be given by the driver over PA, but they may also be conveyed by means of other devices. The blind and low-vision persons can identify free seats onboard vehicle, path towards the exit, etc. by means of small hand receivers. At vehicle arrival to the station, voice devices can be activated by the approaching vehicle (bus or tram) or just by the door opening, so that the waiting passengers can hear the line number and the destination. Based on the obtained information (delay, transfer options, name of the next stop) the passenger can optimize the trip i.e. make dynamic adaptation of the travelling route, e. g. get off the vehicle and continue on foot, stop their own vehicle and continue by public transit, etc. The information at the end of the trip, from the last station of public transit to the destination can be obtained by means of hand computer, electric display, wall maps, etc., and they allow pedestrian navigation to the destination, orientation, provision of important information about the city and completion of information for the next trip.

\subsection{Pedestrian navigation}

The idea of applying the global positioning system and satellite pedestrian navigation is not new, and is used today with great intensity in the developed countries. The pedestrian interaction with this system starts with identifying the target. Based on the known city map the path between two points, along the road axis is plotted. If the destination address is unknown the system requests its input. After identifying the destination, the pedestrian listens to the proposed plan and if it is acceptable the navigation and the path sequence starts, as presented in Figure 8.

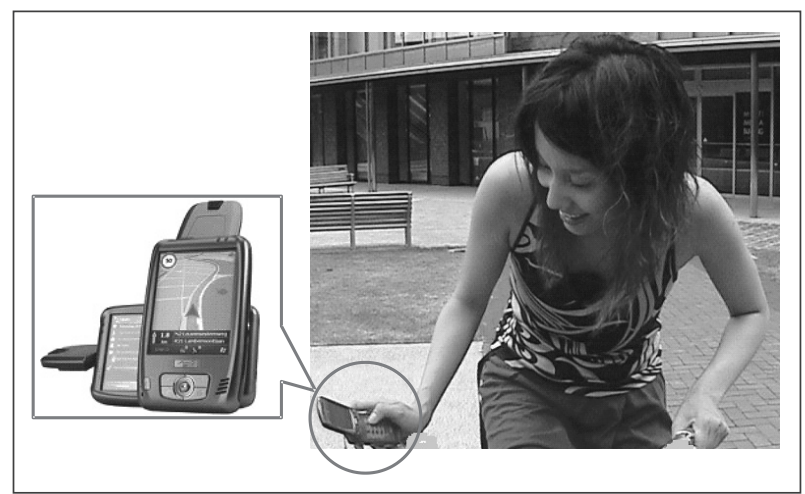

Figure 8 - Graphical interface for pedestrian navigation

Satellite-navigation systems for the pedestrians are of special use to the disabled persons in wheelchairs in unknown environment, and who cannot use certain infrastructure such as fixed staircase due to their disability. The information they receive by voice, graphical and touch interface by using special pens (touch 


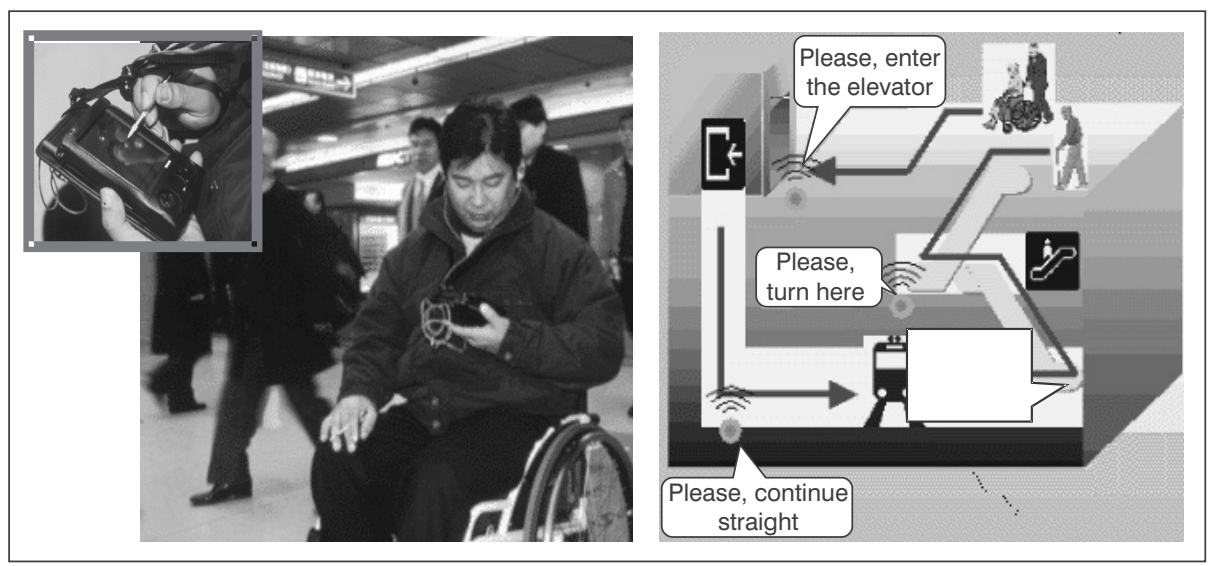

Figure 9 - Pedestrian navigation to the destination using PDA with touch screen interface [24]

screens) shorten the distance and time of travel and navigate them to the destination. The application of such a system, for pedestrian navigation to the escalators, i.e. elevator is presented in Figure 9.

Although this system has huge possibilities, it also features a number of problems. It relies mainly on the maps that are suited to cars, and as such are not acceptable for all the groups of pedestrians, especially not for the blind. In case of the blind persons it should be precisely determined where they may walk along the road, where the road can be crossed, where the barriers are, etc. The current maps are mainly meant for the automobiles where the coordinates pass along the centre of the road, whereas the pedestrians use the pavement and pedestrian crossings. For the automobiles the permitted driving direction on the road is important and there is danger for the pedestrians that they may unnecessarily make detours and walk longer in case the same rules are applied to them. Besides, on city streets, the pavements are on both sides and should be positioned as such on the maps. A large number of pedestrian paths do not follow the streets but these data need to be collected. The automobiles pass through the middle of the intersections, and the pedestrian crossings are some 10 metres before the centre of the intersection. Following such instructions, a low-vision pedestrian would have problems, which means that correction is required here as well. Various atmospheric impacts can negatively affect the precision of pedestrian positioning. High buildings in densely populated areas and subways create barriers to satellite signals so that the GPS receiver cannot always determine the location of the pedestrian. This problem can be solved by local navigation. Problems also occur when data are forwarded to the control centre via classical radio connection. Today, the systems have a built-in GPRS module which uses the network of mobile telephony to send freely the data about the pedestrian to the control centre. These problems are being slowly resolved through the development of advanced technologies. Recently, the GSM telephones are increasingly being mentioned and they provide quite precise positioning of the pedestrian.

Because of the mentioned problems it is a difficult question how to adapt navigation to pedestrians, especially the blind, where high precision is required, because of the possibility of accidental entry into the part of the road used by vehicles. Therefore, one can say that because of safety, GPS navigation adapted for automobiles cannot be used for the blind pedestrians. New solutions are looked for, and these are primarily RFID (Radio Frequency Identification) technologies, infrared sensors, ultrasound sensors, piezoelectric sensors, video surveillance, i.e. other technologies of local navigation (Figure 10).

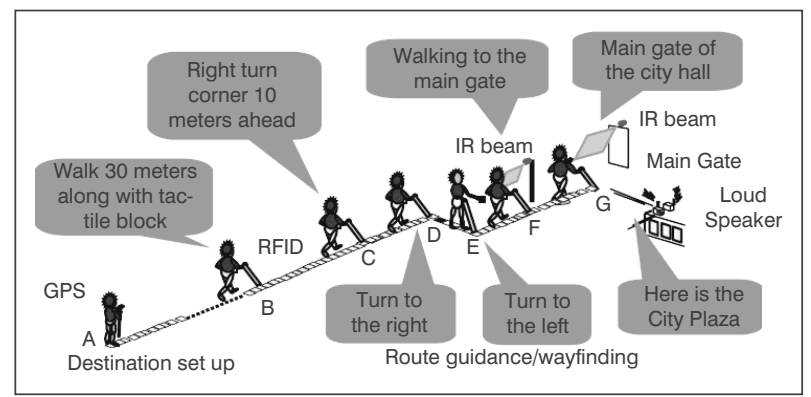

Figure 10 - Pedestrian navigation using RFID technology and IR sensors [25]

RFID technology and various infrared sensors are suitable for tracking persons in city traffic primarily because they are inexpensive, mass produced, active tags last long and are very robust. The main investments in such a system are the readers and adequate program support (software). When a pedestrian passes by a control point the reader records the passage of the pedestrian and forwards the information to the headquarters in real time. The feedback information is returned to the pedestrian in the form of voice messages. The role of the server in this system is to manage the dialogues by means of e.g. voice SML (Service Modelling Language) language. In some cases part of communication is possible also by means 


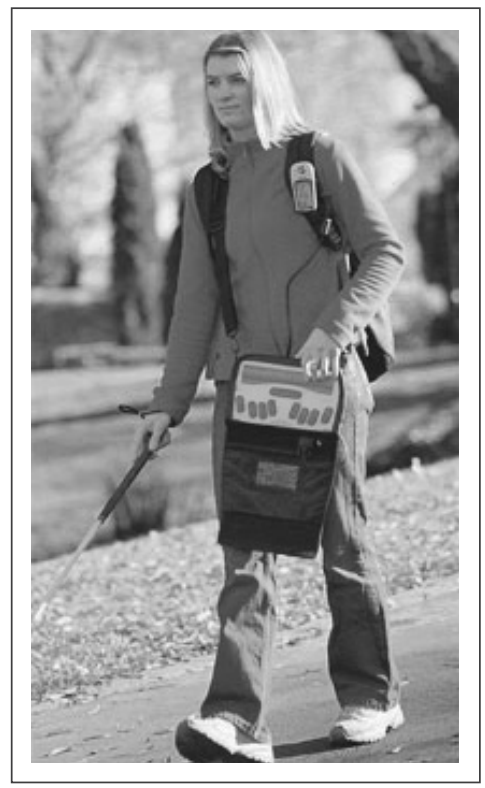

Figure 11 - Pedestrian navigation using Braille alphabet [26]

of the Braille alphabet (Figure 11) where options are selected by means of adequate buttons and the selected options are articulated.

The possible technological solutions of returning voice messages to pedestrians and transmission methods are presented in Figure 12.

Pedestrian navigation using RFID technology and other sensors also has its drawbacks. This type of navigating blind persons is suitable for the installation at a targeted area, on the pre-known routes along which the blind move (from home to the stop, from public transit vehicle to the faculty or centre for the blind, within complex shopping centres, traffic terminals) since it is impossible to cover the entire city by RFID readers. Later, the areas covered by readers can be expanded.

Pedestrians can benefit a lot from the information that are provided to the drivers, by means of variable signals installed along the road (VMS / DMS), especially information that refer to excessive environmental pollution, road condition and weather conditions (black ice, road works, etc.).

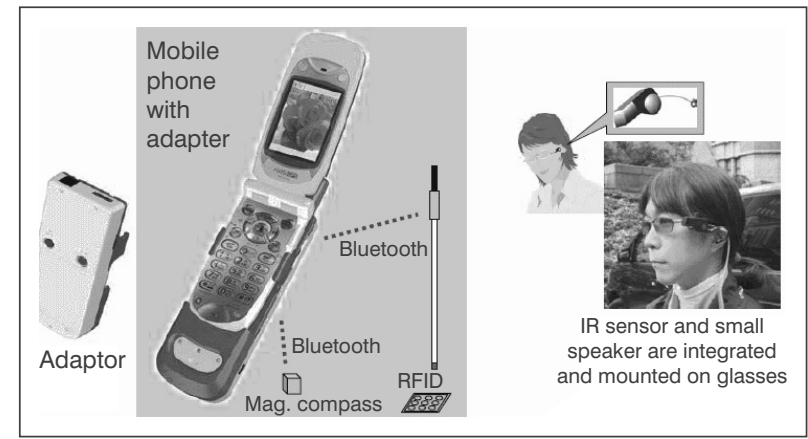

Figure 12 - Voice interface (transmission of voice instructions) [25]

\subsection{Protection of pedestrians on the pedestrian crossing}

Pedestrian crossings are extremely dangerous spots for the pedestrians since this is part of the road they shared with the vehicles, Figure 13.

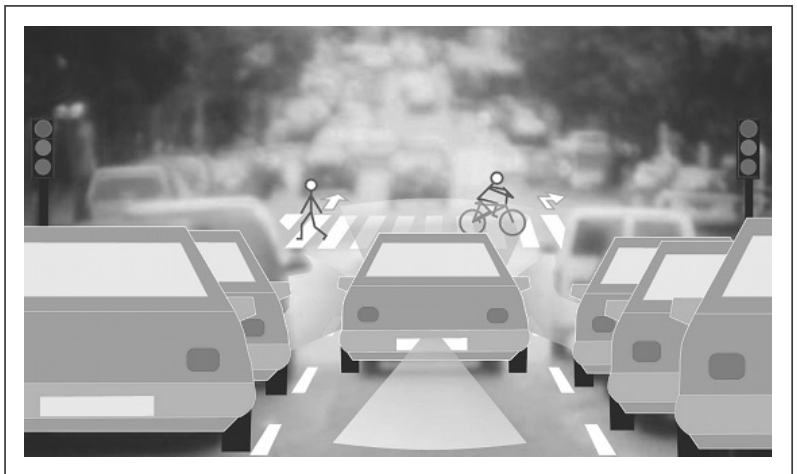

Figure 13 - Pedestrian-vehicle interaction on a pedestrian crossing [27]

In order to increase the safety of pedestrians that can find themselves at the same time with vehicles on the road, the automobiles and roads are fitted with different devices. Special attention is focused on the technologies that assist the driver in avoiding collision with the pedestrian thus directly affecting the traffic safety. The umbrella term for the systems fitted into the vehicle is the Driver Assistance. Their operation is based on different types of sensors that monitor the vehicle environment, provide the driver with information, and even take over control of the vehicle when necessary. Cameras, radars, lasers and ultrasound devices are used as sensors and the most efficient is the combination of several types of sensors (information fusion).

The first forms of assistance referred to the improved driving safety in adverse conditions of movement (darkness, fog or other poor meteorological conditions). Their task was to increase visibility using mostly the systems based on the infrared part of the spectrum. A monitor is located in front of the driver in the vehicle and it displays forms of pedestrians or animals registered by the infrared sensor, based on the heat they emit. The more advanced systems have the possibility of collecting and analyzing the data from the sensors and warn the driver in case of danger. Such a system has a camera which records the path in front of the vehicle and sounds an audio signal in case of danger. An even more complex system has the possibility of forecasting the risk of collision and warning the driver. If it is too late, these systems take over control over the vehicle and try to avoid collision or to alleviate the consequences. This are the so-called active assistance systems installed into high-class vehicles. As part of the INTERSAFE project the area of active protection at intersections has been specially studied. 


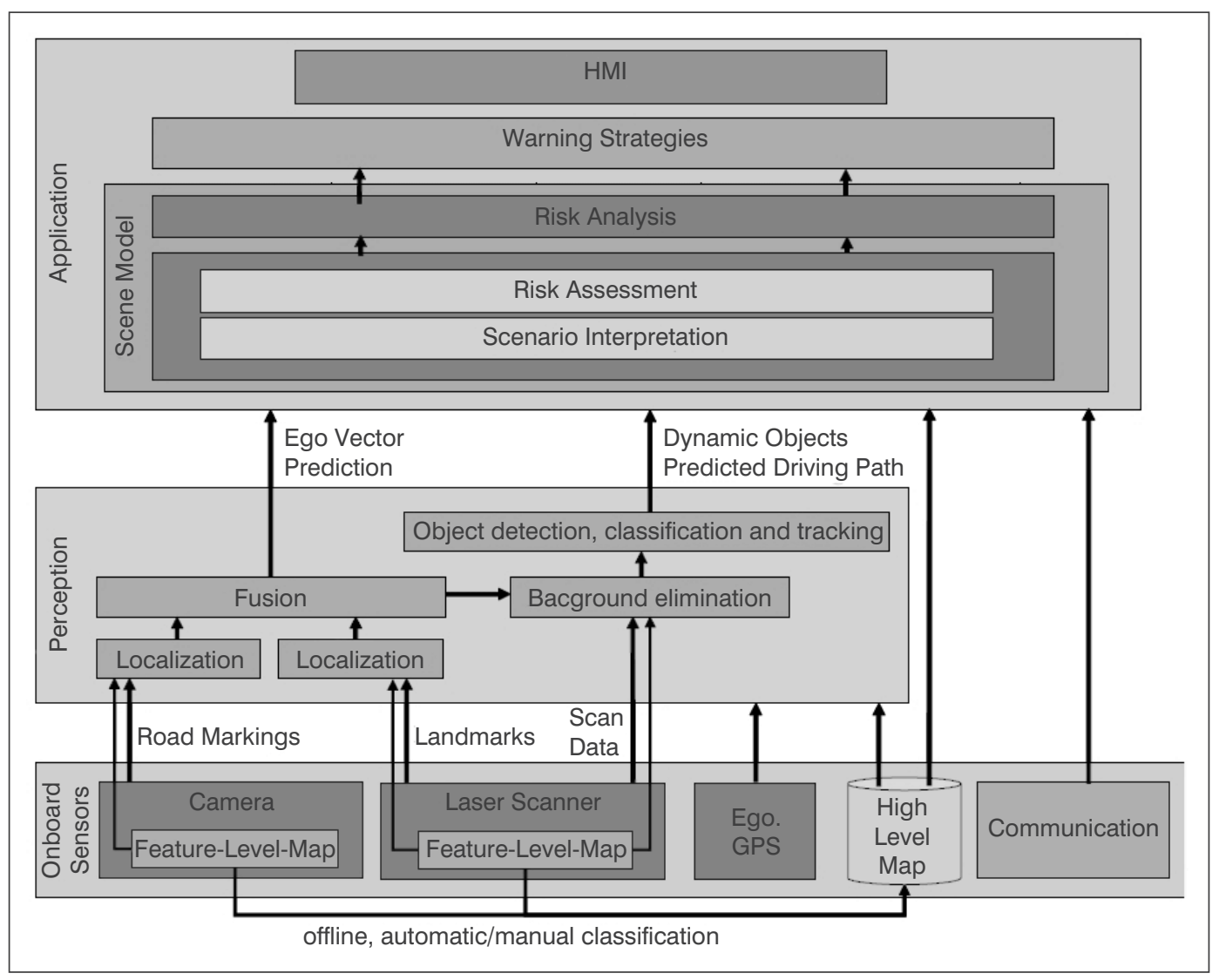

Figure 14 - Active protection system architecture as part of the INTERSAFE project [28]

This is an area in which the pedestrians are the most endangered participants in traffic [28]. Figure 14 shows the proposed architecture.

Other systems can be added to these, such as automatic interpretation of traffic signs and signage, information about the traffic condition on the road, control and adjustment of light in compliance with the driving conditions, automatic parking, etc.

In order to additionally attract the driver's attention and thus increase the safety of passengers, the

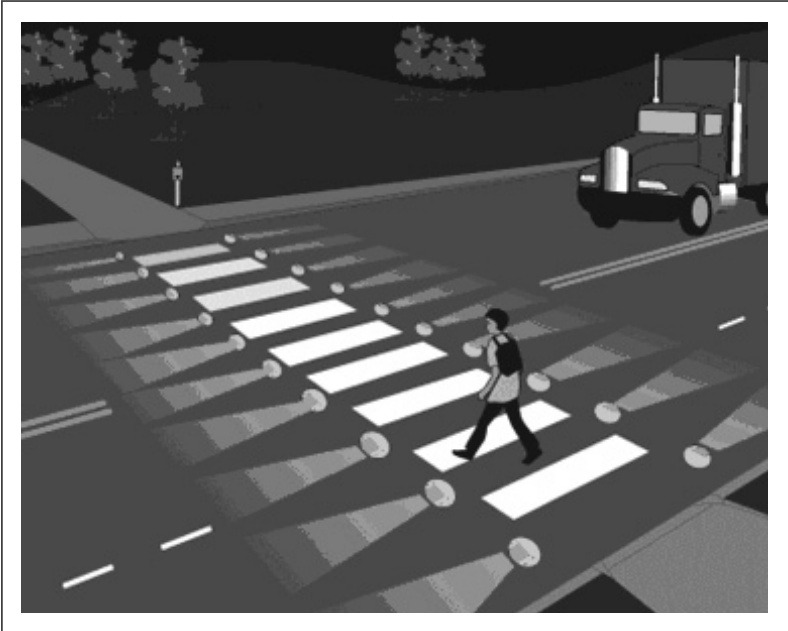

Figure 15 - Passive measure of pedestrian protection $[29,30]$ roads are also fitted with innovative technologies. Until now the attempts were made to increase the visibility of pedestrians on the pedestrian crossing mainly by passive measures (fluorescent tapes, blinking lights, lights embedded in road).

The mentioned systems are efficient but cannot be classified into ITS yet. If sensors were built into the crossings, that would actuate the blinking of light during pedestrian passage along them, then such protection would be significantly improved and could be considered as a certain type of intelligent protection.

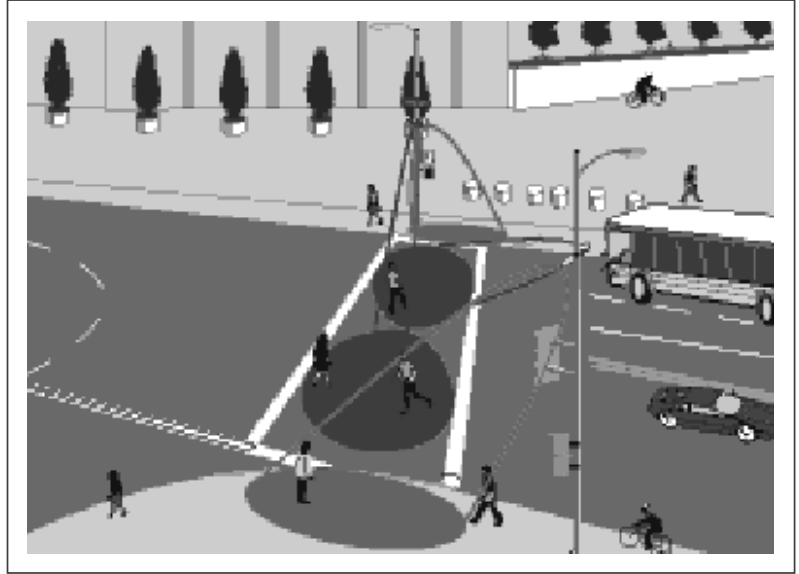

Figure 16 - Online control of light signalization [29, 31] 
Intelligent transport systems operate in real time and usually use two-way communication which means that they have the possibility of immediate adjustment of traffic supply and demand. This advantage can be used in many traffic situations, and one is managing the operation of light signalization. Thanks to two-way communication, at the pedestrian crossings instead of fixed phase cycles the detectors may be used that send data to the control centre where, based on the pedestrian demand the green light is actuated for passengers who wait at the crossing (the actuation criterion can be the waiting time or number of pedestrians) or prolongs the green light for the pedestrian who failed to cross the road before the green phase is over.

At the signal indicator on the pedestrian crossing, a sign can be fitted in the form of eyes that oscillate back and forth at a certain rate and warn the pedestrian to look to both sides before crossing the road and thus increase the safety of crossing [32].

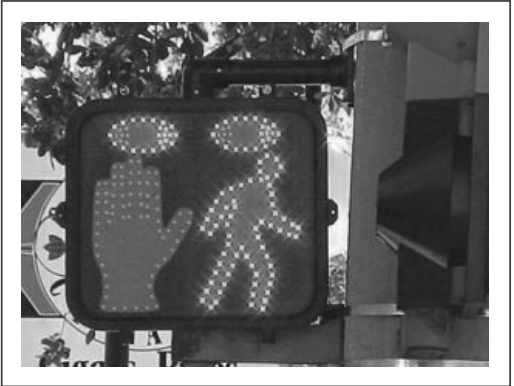

Figure 17 - Display with eye animation [32]

In the world very often the countdowns of traffic cycles are used [33]. They are of special benefit for the disabled persons who use the information on the remaining available crossing time and adapt their speed of moving across the road. Such a dual solution has been installed in Croatia in Varaždin.

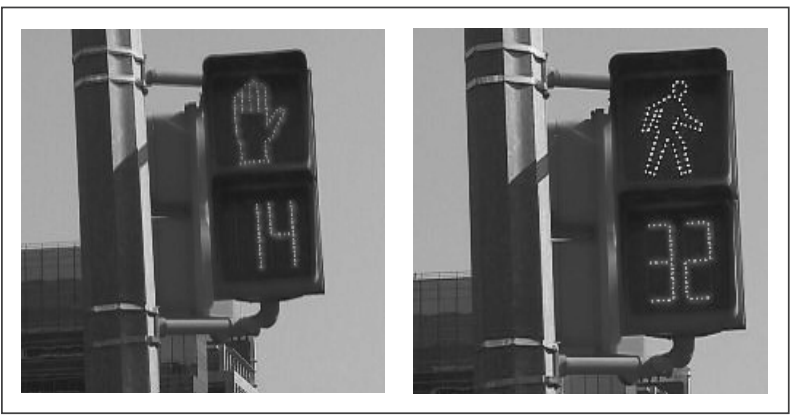

Figure 18 - Traffic light with a countdown for pedestrians [33]

\section{CONCLUSION}

The studies of the problem are related to city traffic and general mobility, and are especially related to the following basic services of ITS: traveller informa- tion, pre-trip and on-trip public transport information, personal information services, route guidance and navigation, traffic management, etc.

Because of lack of space in the city areas it is very difficult to expand the existing roads and construct new roads in order to increase efficiency of traffic by reducing congestion and gridlocks. In pedestrian traffic all the designer measures to increase the passive safety of passengers have been used; lowering of kerbs, extension of kerbs, reducing radii for vehicle turning, measures to calm traffic, construction of tactile paths for navigation of the blind, etc. Obviously, the build-only approach is not long-term sustainable nor an omni-accepted solution of the problem caused by sudden increase in the number of vehicles. Therefore, the attention is focused on better usage of the already existing capacities using ITS upgrade, acceptance of the basic build+ITS principle.

The world experiences have confirmed that ITS integration may significantly improve the efficiency and safety of pedestrian traffic from making the right decisions in multimodal transport, pedestrian navigation to taking over full control over the vehicles in emergency situations, when the lives of pedestrians are endangered.

Past results of applying intelligent transport systems, in many examples of the existing practice worldwide, clearly show that very significant benefits may be obtained with the traffic safety improvement (10$-30 \%$ ). The assumption is that the possible benefits in the Republic of Croatia are even greater, since the basis regarding the safety situation in traffic is much less favourable according to the indicators of the frequency of accidents and fatalities compared to the total population [1].

Using the services provided by intelligent transport systems in traffic, the drawbacks are alleviated and the discrimination of persons with disabilities reduced. Therefore it is very important to pay special attention when building the future ITS architecture in the Republic of Croatia, to pedestrian traffic. Here, a good model may be the approach to ITS in Japan, where one development area is dedicated to pedestrian support.

Holistic development of the Croatian Intelligent Transport System (HITS) understands the national ITS architecture harmonized with the European projects and adapted to the specific features of the Republic of Croatia. It is to be expected with this approach that there will be no errors related to the wide purchase of incompatible equipment, which cannot be part of integral HITS. At this moment it is very important to integrate into the European ideas of ITS development and follow the respective recommendations of the European institutions. It is, namely, in this field that technical standards, as well as EU recommendations may be soon expected [34]. 


\section{Dr. sc. LJUPKO ŠIMUNOVIĆ}

E-mail: ljupko.simunovic@fpz.hr

Dr. sc. IVAN BOŠNJAK

E-mail: ivan.bosnjak@fpz.hr

Dr. sc. SADKO MANDŽUKA

E-mail: sadko.mandzuka@fpz.hr

Sveučilište u Zagrebu, Fakultet prometnih znanosti

Vukelićeva 4, 10000 Zagreb, Republika Hrvatska

\section{SAŽETAK}

\section{INTELIGENTNI TRANSPORTNI SUSTAVI I PJEŠA ČKI PROMET}

U radu je dan pregled dosadašnjeg razvoja i primjene ITS-a u pješačkom prometu. Polazeći od recentnih razvojnih projekata i metodoloških pristupa razvoja ITS-a, pregledno su dane postojeće tehnologije primjene ITS-a u pješačkom prometu te predložena neka rješenja primjenjiva u Republici Hrvatskoj, kao i ostalim zemljama u tranziciji. Kao najvažnije funkcije integriranih sustava u okviru ITS-a, prikazane su mogućnosti lociranja pješaka na mreži, vođenje pješaka (osobito slijepih i slabovidnih te osoba u invalidskim kolicima), pružanje informacija tijekom putovanja i slično. Posebno je obradeno područje zaštite pješaka u prometu (izbjegavanje nesreća) pomoću uređaja ugradenih u vozilima i cestovnu infrastrukturu. Ukazano je na značaj pravodobne integracije pješačkog prometa kod projektiranja buduće arhitekture ITS-a.

\section{KLJUČNE RIJEČI}

inteligentni transportni sustavi (ITS), pješački promet, vođenje pješaka, stvarno-vremenske informacije, sigurnost u prometu

\section{LITERATURE}

[1] I. Bošnjak, S. Mandžuka, Lj. Šimunović: Mogućnosti inteligentnih transportnih sustava u poboljšanju stanja sigurnosti u prometu, Croatian Academy of Arts and Sciences, Zagreb 2007

[2] I. Bošnjak: Inteligentni transportni sustavi 1, University of Zagreb, Faculty of Transport and Traffic Sciences, Zagreb 2006

[3] European Commission and Project partners: FRAME, Planning a Modern Transport System, A Guide to Intelligent Transport System Architecture, Why you need one and how to create it, Issue 2, KAREN, April 2004 http://www.frame-online.net

[4] J. W. Tierolf: FRAME Working with architecture in Europe, Ministry of transport, NL, http://www.frame-online.net

[5] A. Spence, J.W.Tierolf: FRAME-NET, Framework Architecture Made for Europe -Thematic Network, D3.1. European Commission, Report of Work Group on Intermodality, October 2002

[6] J. W. Tierolf: FRAME - Network for European and National ITS Architectures, Brussels, 23. April 2002. http://www.frame-online.net

[7] J. W. Tierolf-Rijkswaterstaat AVV: FRAME - Network for European and National ITS Architectures, Brussels, 23. April 2002.
[8] System Architecture for ITS in JAPAN, National Police Agency, Ministry of International Trade and Industry, Ministry of Transport, Ministry of Posts and Telecommunications, Ministry of Construction, November 5, 1999.

[9] SATIN, Proposals for Urban, Inter-Urban and In Vehicle Architectures, Deliverable $\mathrm{N}^{\circ}$ AC13-PT7, SATIN Task Force, V2056 CORD project of the Advanced Transport Telematics (ATT/DRIVE II) sector of the telematics applications Programme, Third Framework Programme (1991-94), 1995.

[10] CONVERGE, Guidelines for the Development and Assessment of Intelligent Transport System Architectures, Framework IV Transport Telematics Project, CONVERGE (TR1101), Deliverable 2.3, 1998.

[11] KAREN, European ITS Framework Architecture-List of European ITS User Needs, D2.02 - Issue 1, August, 2000.

[12] A. Spence: FRAME, State-of the-art, ITS Architectures in Europe http://www.frame-online.net

[13] T. Yokota, R. J. Weiland: ITS System Architectures For Developing Countries, Technical Note 5, World Bank, July 22, 2004

[14] Integrating Intelligent Transportation Systems within the Transportation Planning Process: An Interim Handbook Prepared for Federal Highway Administration Office of Traffic Management and ITS Applications and Office of Environment and Planning Prepared by TRANSCORE An SAIC Company, January 1998

[15] R. Bossom, P. Jesty, T. Eloranta, O. Le Guellec and A. Nigro: European ITS Framework Architecture - Guide to Configuration Management and ITS Architecture Documentation, European Commission and Project partners, Siemens Traffic Controls, Leeds Innovations, ERTICO, Mizar, Mega, April 2003

[16] Disability Discrimination Act 1995 (c. 50) Office of Public Sector Information, United Kingdom http://www.uk-legislation.hmso.gov.uk/acts/acts1995/ ukpga_19950050_en_1

[17] Special Educational Needs and Disability Act 2001 (c. 10), Office of Public Sector Information, United Kingdom

http://www.uk-legislation.hmso.gov.uk/acts/acts2001/ ukpga_20010010_en_1

[18] Toolkit for Road Transport in Countries with Developing and Transitional Economies, http:// www.developingits.org/itstoolkit

[19] Managing demand through travel information services, u.s. Department of Transportation Federal Highway Administration http://ops.fhwa.dot.gov/publications/ manag_demand_tis/travelinfo.htm

[20] http://gislab.elfak.ni.ac.yu/alexm/ publications/2007/202.pdf

[21] White paper on literature review of real-time transit information systems, White paper literature search and review of current practices in providing real-time transit information, Final august 2002, Battelle 
[22] MLIT, ITS Introduction Guide, Shift from Legacy Systems to Smartway (Internet Connection), prepared by Ministry of Land, Infrastructure and Transport Japan Tokyo, September, 2007.

[23] http://www.calccit.org/itsdecision/ serv_and_tech/Travel_demand_man/ Traveler_information/Enroute_transit_tdm/ enroute_transit_report_tdm.html

[24] http://www.its.go.jp

[25] http://www.its-lectures.ae.keio.ac.jp/2005/ 2005_b_3e.pdf

[26] http://www.pulsedata.com/Products/Notetakers/ BrailleNoteGPS.asp

[27] http://www.invent-online.de

[28] http://www.prevent-ip.org

[29] PedSmart:ITS Applications for Pedestrians http://www.walkinginfo.org/pedsmart
[30] V. P. Sisiopiku: Engineering methods for designing safe pedestrian facilities, The University of Alabama at Birmingham, Birmingham

http://www.ictct.org/workshops/03-Vancouver/

$$
\text { Sisiopiku.pdf }
$$

[31] http://mutcd.fhwa.dot.gov/kno_amend.htm

[32] Ron Van Houten and J.E. Louis Malenfant, The Animated "Eyes" Symbol as Part of the WALK Signal: An Examination of the Generality of its Effectiveness Across a Variety of Intersection Geometries and Timing Parameters, 2001.

[33] H. Huang and C. Zegeer, The Effects of Pedestrian Countdown Signals in Lake Buena Vista, Florida Department of Transportation, November 2000.

[34] I.Bošnjak, S.Mandžuka, S.Pašagić: Zagrebački inteligentni transportni sustav - ZITS, Proceedings of the Conference - Zagreb Development, Zagreb, 2008 